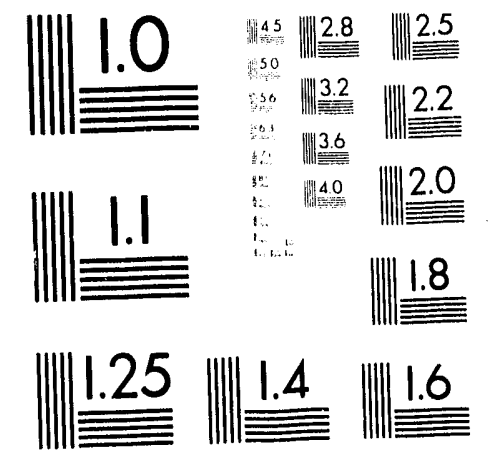



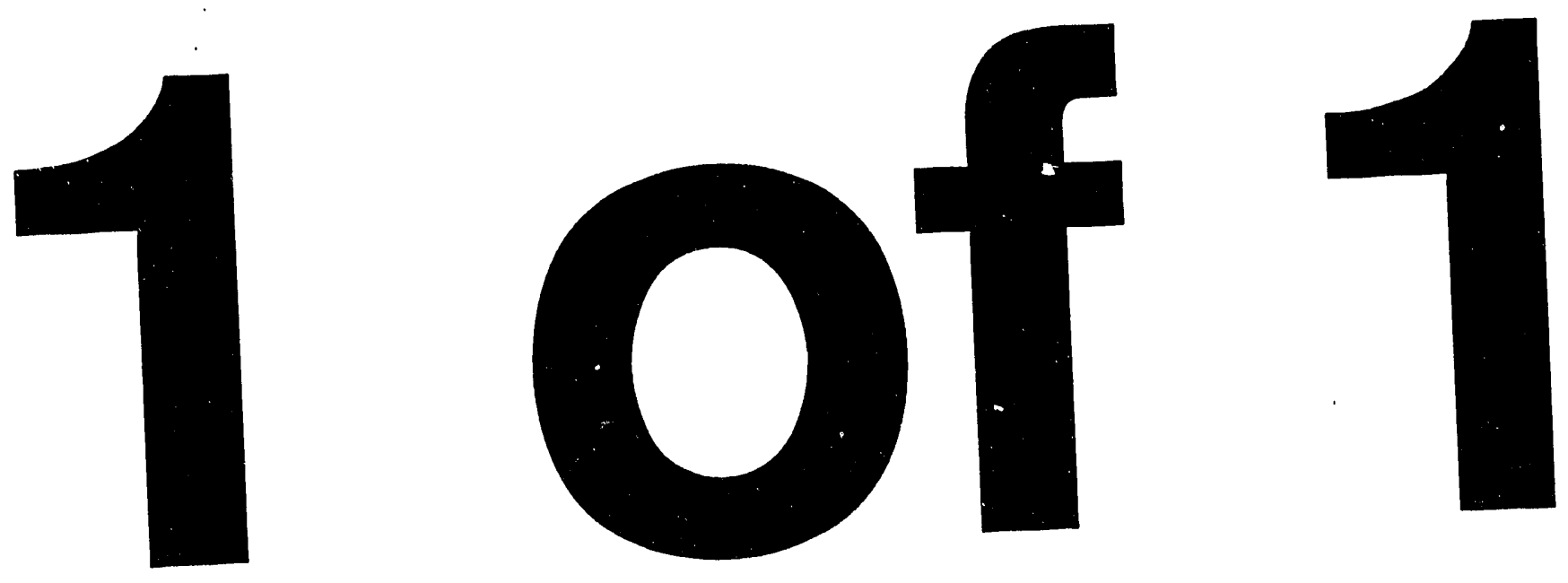


\title{
HIGH-PERFORMANCE SUPERSHOTS IN TFTR WITH LITHIUM PELLET INJECTION
}

\author{
by \\ D. L. Jassby, D. K. Mansfield, M. G. Bell, R. V. Budny, D. R. Ernsta, J. D. Strachan, \\ E. S. Marmarb, J. A. Snipesb, J. L. Terryb, C. E. Bush, E. D. Fredrickson, K. W. Hill, \\ L. C. Johnson, H.K. Park, A. T. Ramsey, E. J. Synakowski, and G. Taylor
}

Princeton Plasma Physics Laboratory, Princeton University

P.O. Box 451, Princeton, NJ 08543

\begin{abstract}
Increasing the amount of lithium pellet injection during the supershot conditioning procedures has enabled reliable enhancement of supershot confinement at higher plasma currents. Some shots have exceptionally good performance, with peak global parameters up to $\tau_{\mathrm{E}}=205 \mathrm{~ms}, \mathrm{~S}_{\mathrm{n}}=5.6 \times 10^{16} \mathrm{n} / \mathrm{s}$ and $\mathrm{QDD}=2.1 \times 10^{-3}$.
\end{abstract}

\footnotetext{
aAlso at Mass. Inst. of Tech., Cambridge, MA

bPlasma Fusion Center, Mass.Inst. of Tech., Cambridge , MA
}

PPPL-2940

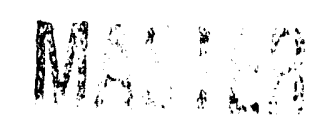

September 1993 


\section{Introduction}

TFTR supershots are neutral-beam-fueled and heated plasmas with enhanced confinement characterized by highly peaked density profiles and relatively broad temperature profiles. The basic technique for achieving supershot operation is to inject high-power neutral beams into a low-density target plasma with a first wall/limiter that has been conditioned to achieve a low recycling coefficient [1]. Aggressive limiter conditioning procedures [2] have included Ohmic helium discharges to remove deuterium from the carbon limiter; repetitive high-power neutral-beam injection (NBI); disruptive discharge cleaning; and inducement of runaway sublimation of carbon from the limiter (a "carbon bloom") on the previous shot. For several years, supershots were limited to plasma currents, $I_{p}$, below about 1.5 MA, because higher $\mathrm{I}_{\mathrm{p}}$ was apparently correlated with increased deuterium recycling and carbon influx from the limiter. However, supershot performance at lower $I_{p}$ is limited by MHD constraints. In particular, the pressure limit (evidenced by minor or major disruption, often at $\beta_{p}=1.2$ ) appears to increase with $I_{p}$ in a manner similar to the Troyon limit [3]. The performance of supershots approaching the $\beta$ limit tends to degrade after about $0.5 \mathrm{~s}$ of beam injection, often because of the start of coherent MHD (such as 3/2 or 4/3 modes), or because of a disruptive MHD event $[3,4]$. Thus the ability to operate at higher $I_{p}$ is essential.

In 1990, with the aid of a single pre-beam lithium pellet injected $1.0 \mathrm{~s}$ before NBI, the carbon influx was significantly reduced, and the high-performance supershot range extended to 1.9 MA, with consequent increases in plasma stored energy, $\mathrm{E}_{\text {tot, }}$ and the maximum neutron rate, $S_{n}[5]$. Lower carbon-II emission from the target plasma and lower $Z_{\text {eff }}$ during NBI suggested that pre-beam lithium pellet injection reduced the carbon influx by covering the active limiter surfaces with lithium. In 1992 this procedure was extended by injecting two lithium pellets in the Ohmic phase of each beam shot, by using pellets twice as large as in 1990, and also by operating a series of Ohmic shots with lithium pellet injection prior to the ber.m shots. This paper describes the best plasmas achieved during the 1992 campaign.

\section{Experiment}

The conditioning sequence for a supershot run often began with a series of 1.4-MA helium Ohmic plasmas that were repeated until the rate of carbon influx (which is characterized by the carbon-II emission level [6]) ceased dropping from shot to shot. This series was often followed by a series of 1.4-MA ohmic deuterium plasmas with Li pellet injection, also repeated until the magnitude of carbon-II emission stopped evolving. It is 
assumed that this second phase established a preliminary coating of $\mathrm{Li}$ on the limiter. The methodology of the $1992 \mathrm{Li}$ pellet conditioning is described more fully elsewhere [7].

Figure 1 shows the time evolution of the central and edge electron densities, as well as the $\mathrm{D}_{\alpha}$ and CII emission, for one of the best Li-assisted supershots (\#68244) and a comparison supershot plasma without Li pellets (\#68206). Two Li pellets were injected into the Ohraic target plasma about $1 \mathrm{sec}$ before the start of neutral-beam injection (NBI), so that the Li would transport out of the plasma and cover the carbon inner wall, which is employed as a bumper limiter. The plasma density, $n_{e}$, and carbon influx returned to levels slightly below the initial levels that would have occurred if the pellets were not injected [8]. Starting from this low-density target plasma, beam fueling resulted in a rapid rise in $\mathrm{n}_{\mathrm{e}}$ and strong peaking of the density profile. The plasma evolution during beam heating also featured lower carbon and deuterium influxes as well as lower edge density when the plasma was aided by $\mathrm{Li}$ pellets. However, the Li-assisted plasma had significantly higher central density, $\mathrm{n}_{\mathrm{e}}(0)$.

For supershots, the neutron emission rate, $S_{n}$, is nearly proportional to $E_{\text {tot }}{ }^{2}$ [3]. Higher performance at a given beam power (i.e., higher $S_{n}$ and $E_{\text {tot }}$ ) is generally associated with higher energy confinement time, $\tau_{\mathrm{E}}$, as $\mathrm{E}_{\text {tot }} \approx \mathrm{P}_{\mathrm{b}} \tau_{\mathrm{E}}$, where $\mathrm{P}_{\mathrm{b}}$ is the injected neutrai-beam power. At a given $\mathrm{P}_{\mathrm{b}}$, the 1992 supershots with Li pellet conditioning generally gave higher $S_{n}$ than the supershots of previous years [4]. The 1992 supershots often had higher $\tau_{\mathrm{E}}$ than in 1990, and in particular, a much larger proportion had $\tau_{\mathrm{E}}>0.15 \mathrm{~s}$. This result is probably due to the larger number of $\mathrm{Li}$ pellet shots in 1992, the larger amount of $\mathrm{Li}$ in each pellet, and the use of $2 \mathrm{Li}$ pellets per shot. In fact, as shown in Fig. 2, the supershot $\tau_{\mathrm{E}}$ increases with $\mathrm{Li}$ light intensity from the target plasma. The light intensity is probably proportional to the amount of $\mathrm{Li}$ on the limiter and in the plasma edge, and there is apparently no saturation of $\tau_{\mathrm{E}}$ with the levels of $\mathrm{Li}$ used to date.

Confinement time also appears to be associated favorably with density peakedness, $\left.\mathrm{n}_{\mathrm{e}}(0) /<\mathrm{n}_{\mathrm{e}}\right\rangle$, and higher peakedness probably results from a larger fraction of the central density fueled by the beams. Higher peakedness has generally been correlated with lower carbon emission from the target plasma, and often with lower target density $[3,4,7]$. With reduced recycling apparently a result of $\mathrm{Li}$ covering the limiter, $\mathrm{Li}$ pellet injection enables still higher peakedness (and sometimes lower $\mathrm{Z}_{\text {eff }}$ ). These correlators are not unique, but the important feature is that the Li-assisted plasmas comprise an extension of supershot performance and are not an intrinsically new phonomenon. 


\section{Exceptional Shots}

During 1990-92, the median $\tau_{\mathrm{E}}$ for $\mathrm{Li}$-assisted supershots was about $150 \mathrm{~ms}$, compared with $135 \mathrm{~ms}$ for all supershots (excluding those with RF power). While only $9.5 \%$ of all supershots had $\mathrm{Li}$ conditioning, these accounted for $37 \%$ of supershots with $\tau_{\mathrm{E}}>170$ ms and $50 \%$ with $\tau_{\mathrm{E}}>180 \mathrm{~ms}$. In 1992 , several plasmas had exceptionally good performance with maximum $\tau_{\mathrm{E}}=185-205 \mathrm{~ms}$. (Note that the largest $\tau_{\mathrm{E}}$ during NBI usually occurred somewhat earlier than the time of maximum $S_{n}$.) Each of these exceptional shots came after sequences of plasmas aimed at successively accumulating more $\mathrm{Li}$ on the limiter. However, the occurrence of such plasmas was sporadic, and presently not fully understood. Table 1 gives the parameters of 4 of these shots, which were obtained after different sequences of $\mathrm{Li}$ conditioning [7] (on different days), and they are characterized by different levels of $\mathrm{I}_{\mathrm{p}}$ and $\mathrm{P}_{\mathrm{b}}$. The parameter values shown are taken at peak $S_{n}$. Also shown are the parameters for \#68206, a comparison shot that had the same machine settings as \#68244, but that occurred during the early part of the sequence before any Li pellets were injected (see also Fig. 1). Evidentiy, $\mathrm{n}_{\mathrm{e}}(0), \mathrm{T}_{\mathrm{e}}(0)$ and $\mathrm{T}_{\mathrm{i}}(0)$ are substantially larger for the high- $\tau_{\mathrm{E}}$ plasmas.

Figure 3 compares the time evolution of several parameters for shots 68206 and 68244 , as well as for shot 68522 , which gave record $E_{t o t}$ and $Q D D$ but at substantially higher $\mathrm{P}_{b}$ and $\mathrm{I}_{\mathrm{p}}$ than 68244. $\mathrm{T}_{\mathrm{e}}$ was determined from cyclotron radiation (ECE), $\mathrm{T}_{\mathrm{i}}$ from charge-exchange recombination spectroscopy (CHERS), and $\mathrm{n}_{\mathrm{e}}$ from multi-channel laser interferometry. The following is a discussion of the performance of the 4 exceptional shots of Table 1.

Shot 68244. On this run day there were no Ohmic shots with Li pellet pre-conditioning. However, shot 68244 was preceded by a series of beam shots with 1 pre-beam and 1 post-beam $\mathrm{Li}$ pellet, this series having $\tau_{\mathrm{E}} \approx 160-170 \mathrm{~ms}$. Shot 68244 , as well as the immediately preceding two shots (68242 and 68243), had 2 pre-beam Li pellets. Shot 68242 attained $\tau_{\mathrm{E}}=190$ $\mathrm{ms}$, but suffered MHD problems beginning at $0.4 \mathrm{~s}$ after NBI, while $\tau_{\mathrm{E}}$ for $\# 68243$ was $170 \mathrm{~ms}$. Shot 68244 proceeded with $\tau_{\mathrm{E}}=180$ to $190 \mathrm{~ms}$ for a longer time than in 68242 , so that $\mathrm{n}_{\mathrm{e}}(0)$ and $S_{n}$ could continue to build up until about $0.6 \mathrm{~s}$ into the beam pulse, when $\beta_{\mathrm{p}}$ reached 1.20 and the central plasma parameters began to degrade.

Figure 4 compares some radial profiles for $\# 68244$ with the corresponding profiles for the non-pellet shot 68206 . The Li-conditioned shot has central electron density $35 \%$ higher for essentially the same average density, $25 \%$ higher $\mathrm{T}_{\mathrm{e}}(0)$, and $37 \%$ higher $\mathrm{T}_{\mathrm{i}}(0)$. While $\mathrm{T}_{\mathrm{e}}(\mathrm{r})$ has the same FWHM for both shots, $\mathrm{T}_{\mathrm{i}}(\mathrm{r})$ is slightly broader for the pellet shot. The $30 \%$ 
higher $\tau_{\mathrm{E}}$ of $\# 68244$ is reflected in the much larger density in a higher temperature central region. The larger $n_{e}(0)$ results in a reduction in the (calculated) beam-ion density and the beam-beam reaction rate, but the total neutron rate is dominated by increases in the thermal and beam-target rates. The more highly peaked density profile and higher $\mathrm{T}_{\mathrm{i}}$ enhance the thermal reaction rate, while the higher $\mathrm{T}_{e}$ and $\mathrm{T}_{i}$ tend to increase the be:m slowing-down time. (The density effect cancels out of the beam-target rate.) The resultant neutron rate is $60 \%$ higher for the shot aided by $\mathrm{Li}$ pellet conditioning.

Shot 68436 . The series of shots around 68436 had the same $I_{p}$ as the 68244 series, but used lower $\mathrm{P}_{\mathrm{b}}$ in an attempt to reduce MHD problems. A large $\tau_{\mathrm{E}}(160-180 \mathrm{~ms})$ was obtained in the first beam shots after a sequence of Li-conditioned ohmic shots. Shot 68436 had an unusually large $\tau_{\mathrm{E}}$ that reached $205 \mathrm{~ms}$, but its $\mathrm{S}_{\mathrm{n}}$ was matched by two others in the sequence. Despite the lower $\mathrm{Pb}_{\mathrm{b}}$, salient parameters such as $\mathrm{S}_{\mathrm{n}}$ began to degrade at $0.5 \mathrm{~s}$ into the beam pulse, when $\beta_{p}$ was still only 1.06. The apparent cause was a minor disruption followed by increased MHD activity and carbon influx.

Shot 69162. This shot was the last of a long sequence of beam shots with $2 \mathrm{Li}$ pellets in the pre-beam phase. The preceding shot (\#69161) differed in that $2 \mathrm{Li}$ pellets were injected into the post-beam phase, at $\mathrm{t}=3.9$ and $4.3 \mathrm{~s}$. Thus \#69162 benefited from $4 \mathrm{Li}$ pellets and its $\tau_{\mathrm{E}}$ was $20 \%$ larger than for most of the preceding shots. (A similar arrangement with a total of 2 pellets was made for \#55806, the highest-S $S_{n}$ shot of 1990 [4].) The 69162 plasma disrupted at $0.48 \mathrm{~s}$ into the beam pulse, as the large $\tau_{\mathrm{E}}$ allowed $\beta_{\mathrm{p}}$ to rise to 1.26 and $\beta_{\mathrm{N}}$ to 2.2.

Shot 68522. This shot was the 2nd beam shot following a sequence of ohmic shots with $\mathrm{Li}$ pellet conditioning. The 1 st beam shot (\#68521) had a carbon bloom, probably aiding the conditioning process in a manner that has been well-documented on TFTR but not understood [2]. (A similar event occured before \#47394, which in 1990 gave the record QDD for non-Li-conditioned shots.) Shot 68522 gave the highest $E_{t o t}, S_{n}$ and $Q D D=S_{n} / P_{b}$ of any TFTR shot to date, before disrupting at $0.5 \mathrm{~s}$ into the beam pulse, at $\beta_{\mathrm{p}}=1.20$ and $\beta_{\mathrm{N}}=2.1$.

These results show that major or minor MHD events or carbon bloom can restrict the period of maximum stored energy and neutron rate of the best supershots to about $0.5 \mathrm{~s}$ or less. Thus there is a need to increase the stability margin by operating supershots at still 
higher $I_{p}$. The maximum $I_{p}$ for which supershot confinement was obtained during 1992 was 2.45 MA, in plasmas that used Li pellet conditioning [7]. At this $I_{p}, \tau_{E}=160$ ms was observed at $\mathrm{Pb}$ up to 28.5 MW (shot 69060). However, density peakedness was a relatively moderate $2.3, \beta_{p}$ was only 0.6 , and $S_{n}$ at $3.4 \times 10^{16} \mathrm{n} / \mathrm{s}$ was somewhat smaller than the best values obtained at this $\mathrm{P}_{\mathrm{b}}$ using lower $\mathrm{I}_{\mathrm{p}}$ (see Fig. 2). The low $\beta_{\mathrm{p}}$ does indicate considerable potential for improved performance, probably by injecting greater Li mass per pulse.

\section{Code Simulations}

The TRANSP code [9] was used to calculate the time dependence of thermal, beamthermal, and beam-beam reactions. As indicated in Fig. 5 for shot 68522, the total neutron rate calculated by TRANSP, using the measured temperature and density profiles, is in good agreement with the measured rate. Initially, beam-beam reactions are dominant, until the target density builds up by beam fueling. After about one-half second of beam injection, this highest performing shot acquires the canonical supershot distribution of reaction rates: Beam-target reactions account for $55 \%$ of the total rate, with the balance shared roughly equally by beam-beam and thermal-ion reactions [4].

Using the measured radial profiles of plasma parameters, the SNAP code [10] determines particle and heat transport coefficients, $D_{e}, \chi_{e}$, and $\chi_{i}$. Both heat diffusion and convection are included in $\chi_{e}$, and $\chi_{i}$. Figure 6 compares, for each transport coefficient, the radial profile of the median value for 5 exceptional shots ( 3 of the 4 discussed herein, plus 2 shots fairly similar to \#68436), with the profile of the median value for 180 supershots with no Li conditioning, also from the 1992 campaign. The profiles are shown at the time of peak neutron emission. While the radial profiles of $n_{e}, T_{e}$ and $T_{i}$ are distinctly different for the two categories (see Fig. 4), the calculation of gradients necessary for determining transport coefficients results in a large spread in values at each r/a, within. each category.

The values of $\mathrm{D}_{\mathrm{e}}$ and $\chi_{\mathrm{e}}$ for the exceptional Li-conditioned shots are fairly similar (within statistical deviation) to the values for the non-Li shots, but the exceptional shots have somewhat smaller $\mathrm{D}_{\mathrm{e}}$ and $\chi_{\mathrm{e}}$ at $\mathrm{r} / \mathrm{a}<0.5$. (There was incomplete $\mathrm{T}_{\mathrm{e}}$ data at $\mathrm{r} / \mathrm{a}>0.5$.) The values of $\chi_{i}$ for the exceptional $\mathrm{Li}$-conditioned shots are as much as a factor of 2 smaller than those for the non-Li shots at $\mathrm{r} / \mathrm{a}<0.6$. Thus the improvement in $\tau_{\mathrm{E}}$ appears to be due mainly to a large reduction in ion heat transport.

The radial profiles of the average values of the transport coefficients for 30 other supershots with $\mathrm{Li}$ pellet injection in 1992 generally fall between those shown in Fig. 6 . These 
results are consistent with the measurements of substantially larger global $\tau_{\mathrm{E}}$ for supershots with $\mathrm{Li}$ pellet conditioning, and especially for the exceptional shots.

\section{Conclusions}

Supershot performance in TFTR can be enhanced substantially by the use of lithium pellet injection to condition the inner wall during the ohmic phase of the beam pulse. In such cases the global energy confinement time can reach $200 \mathrm{~ms}$ for exceptional shots, and the peak neutron rate can exceed the nominal supershot envelope by $20 \%$, even at $I_{p}=1.8-2 \mathrm{MA}$ where previous performance without $\mathrm{Li}$ pellets had been lower than for $\mathrm{I}_{\mathrm{p}}<1.5 \mathrm{MA}$. Exceptional shots were sometimes preceded by a shot having a special conditioning feature, such as a carbon bloom or $\mathrm{Li}$ pellet injection in the post-beam phase. The best shot achieved $5.6 \times 10^{16} \mathrm{n} / \mathrm{s}$ and $\mathrm{QDD}=2.1 \times 10^{-3}$ just before disruption.

More work is required to achieve superior supershots at $I_{p}$ up to $2.5 \mathrm{MA}$, in order to avoid the $\beta$ limit that restricts performance at lower $I_{p}$. Increases in $\tau_{E}$ are generally correlated with greater amounts of injected $\mathrm{Li}$, and no saturation of the benefits of lithium injection has yet been observed, so that future experiments will utilize greater Li mass injection per pulse.

\section{Acknowledgment}

The authors thank M. Vocaturo for operating the Li pellet injector and Dr. G. Wurden of Los Alamos National Lab. for supporting analysis. The authors acknowledge the support of R.J. Hawryluk, J.C. Hosea, D.M. Meade, K.M. McGuire, and K.M. Young, and the cooperation of the TFTR tokamak operations and neutral beam groups. The authors thank D.R. Mikkelsen and S. Picher for useful comments.

This work was supported by the U.S. Dept. of Energy Contract No. DE-AC02-76-CHO-3073. 


\section{References}

[1] J.D. Strachan, et al., Phys. Rev. Lett. 58, 1004 (1987).

[2] M. Ulrickson, et al., Plasma Physics and Controlled Nuclear Fusion Research 1988 (IAEA, Vienna 1989), Vol. III, p. 419; also J.D. Strachan, et al., J. Nucl. Mat. 196-198, 28 (1992).

[3] M.G. Bell, et al., Plasma Physics and Controlled Nuclear Fusion Research 1988 (IAEA, Vienna 1989), Vol. I, p. 27.

[4] D.L. Jassby, et al., Phys. Fluids E 3, 2308 (1991).

[5] J.L. Terry, et al., Plasma Physics and Controlled Nuclear Fusion Research 1990 (IAEA, Vienna 1991), Vol. I, p. 393.

[6] A.T. Ramsey and S.L. Turner, Rev. Sci. Instrum. 58, 1211 (1987).

[7] J.D. Strachan, et al., Princeton Plasma Physics Lab. Report, in preparation.

[8] J.A. Snipes, et al., in Proc. 18th Europ. Conf. on Controlled Fusion and Plasma Heating (EPS, 1991), Vol. 3, p. 141.

[9] R.V. Budny et al., Nucl. Fusion 32, 429 (1992).

[10] H.H. Towner, et al., Rev. Sci. Instrum. 63, 4753 (1992). 
Table 1

\section{PARAMETERS OF BEST 1992 LITHIUM PELLET SUPERSHOTS}

(Ref.shot)

$\# 68436$

$\# 69162$

\#68522

$\# 68244$

\#68206

$B_{t}(T)$

4.73

5.0

5.0

4.73

4.73

$R_{0}(m)$

2.45

2.54

2.52

2.45

2.45

$I_{p}(M A)$

1.64

1.75

2.0

1.64

1.64

$\mathrm{P}_{\mathrm{b}}(\mathrm{MW})$

17.8

28.2

30.8

20.6

20.8

Li pellets

2

$2(+2)$

2

2

0

$E_{b}(k e V)$

100

103

107

102

102

$\mathrm{T}_{i}(0), \mathrm{keV} \quad 30$

27

28

20

$\mathrm{T}_{e}(0), \mathrm{keV}$

9.4

10.0

10.5

10.6

8.4

$n_{\theta}(0), m^{-3}$

5.8 E19

10.5 E19

9.7 E19

7.6 E19

5.6 E19

$\left.n_{\theta}(0) /<n_{\theta}\right\rangle$

2.6

3.2

3.25

2.9

2.1

$\tau_{E}(\mathrm{~ms}) *$

195

185

195

185

140

$z_{\text {eff }}$

$2-3$

$2-3$

$2-3$

2-3

3-4

Plas.En'gy (MJ) $\quad 3.0$

4.6

5.5

3.6

2.8

$\beta_{p}$

1.06

1.26

1.20

1.20

0.92

$s_{n}(n / s)$

2.2 E16

4.3 E16

5.6 E16

$3.1 \mathrm{E} 16$

$1.9 \mathrm{E} 16$

ODD

$1.45 E-3$

$1.78 \mathrm{E}-3$

$2.13 E-3$

$1.76 E-3$

1.07 E-3

Comment:

Minor Disrup. Major Disrup

$0.5 \mathrm{~s}$ into

$0.48 \mathrm{~s}$ into

0.5 s into

0.6 s into

Slow improv.

beam pulse beam pulse beam pulse beam pulse

through beam pulse

\footnotetext{
"Measured at peak $S_{n}$
} 

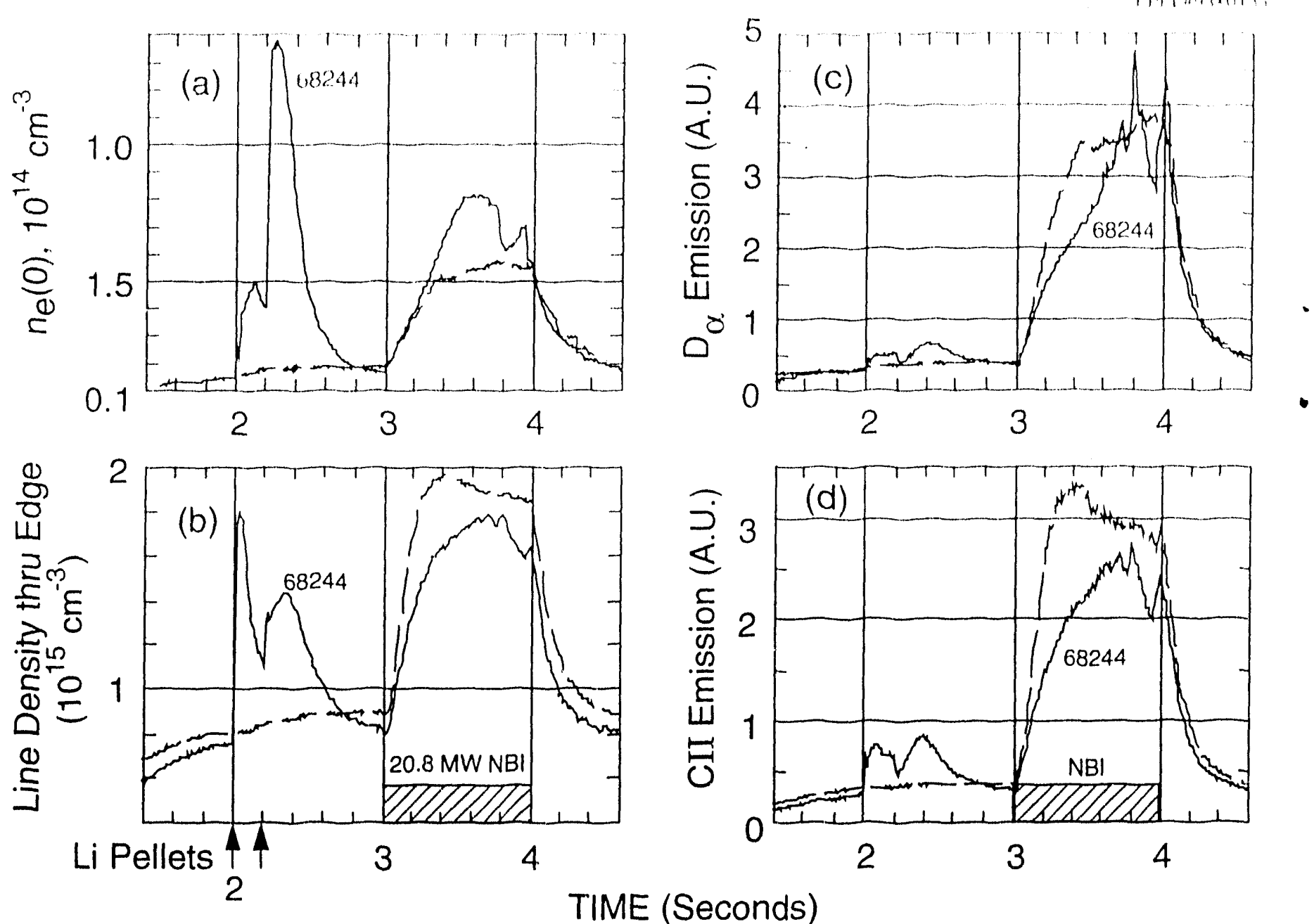

Fig. 1. Time dependence of (a) central electron density, (b) line-averaged density through the plasma edge, (c) $\mathrm{D}_{\alpha}$ emission, and (d) C-II emission for shot 68244 with lithium pellet injection at 2.0 and $2.2 \mathrm{~s}$, and comparison shot 68206 with no pellets. Neutral beams are injected from 3.0 to $4.0 \mathrm{~s}$ in both cases. 


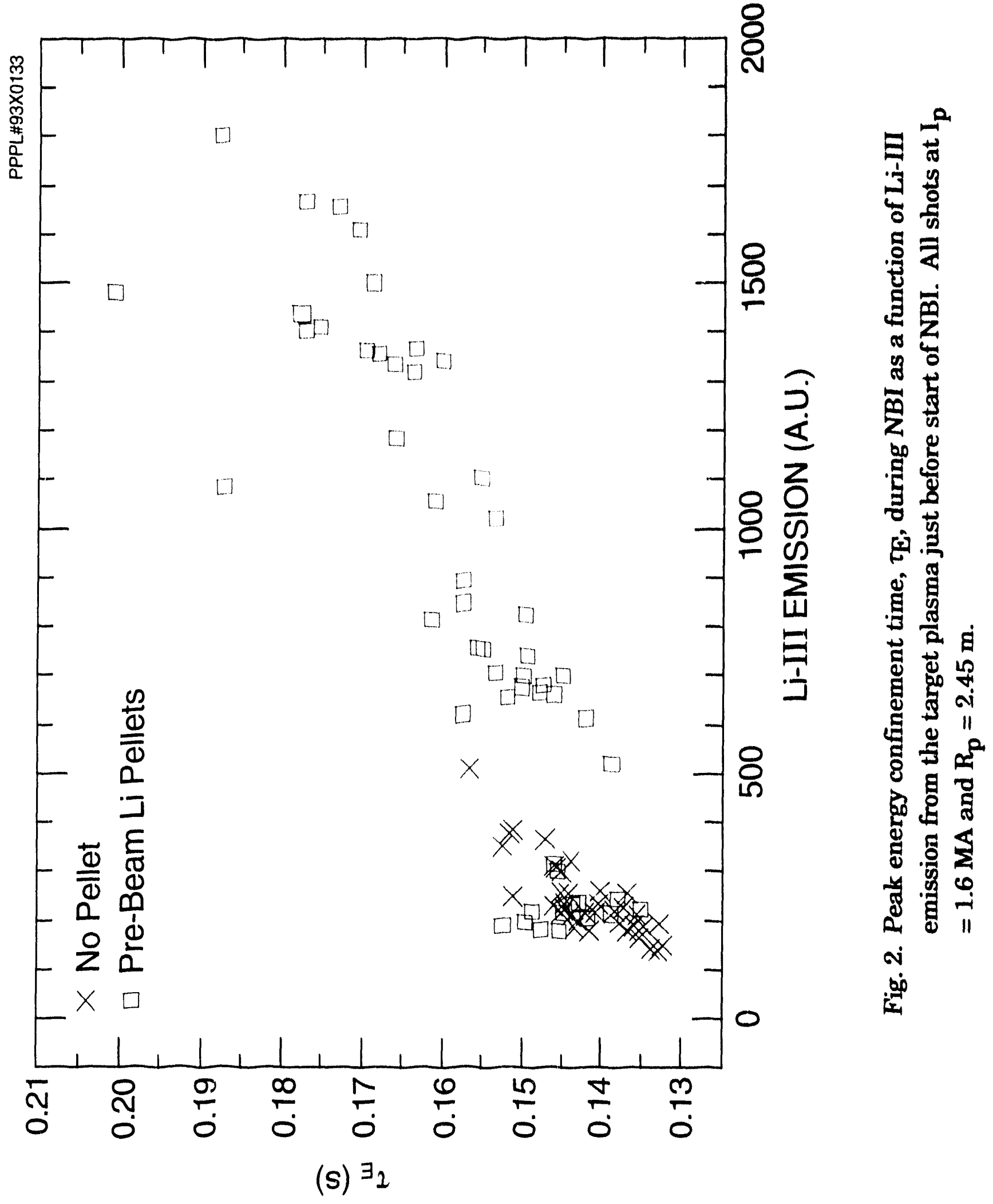


PPPL $\$ 93 \times 0134$
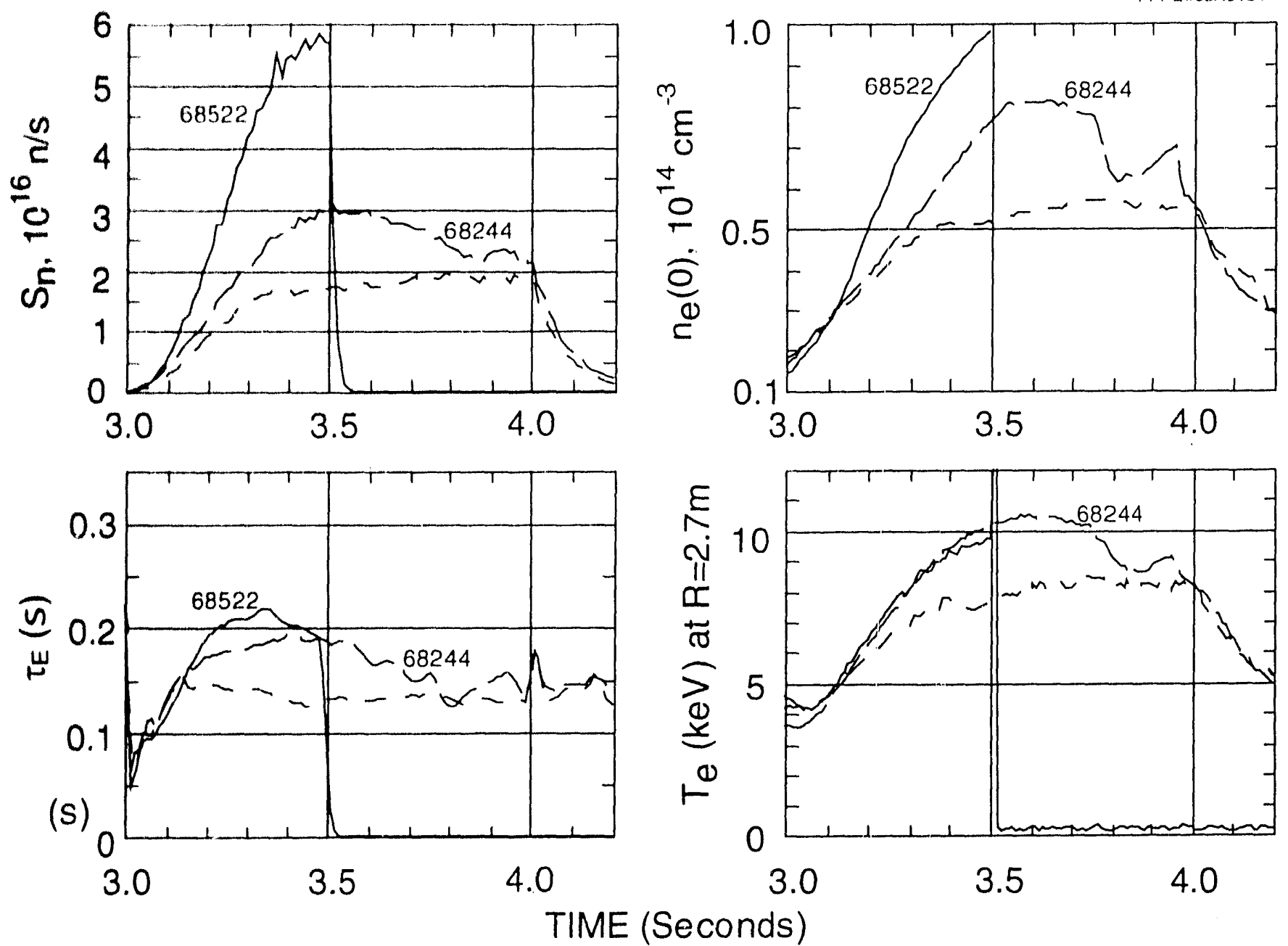

Fig. 3. Time dependence of $S_{n}, \tau_{E}, n_{e}(0)$ and $T_{e}$ at $\AA=2.7 m$ (near the plasma center) for shot 68244 with $\mathrm{Li}$ pellet injection, comparison shot 68206 (no pellets), and the shot with record values of $S_{n}$ and $E_{\text {tot }}, \# 68522$, which disrupted at $3.5 \mathrm{~s}$. Neutral beams are injected from 3.0 to $4.0 \mathrm{~s}$. 

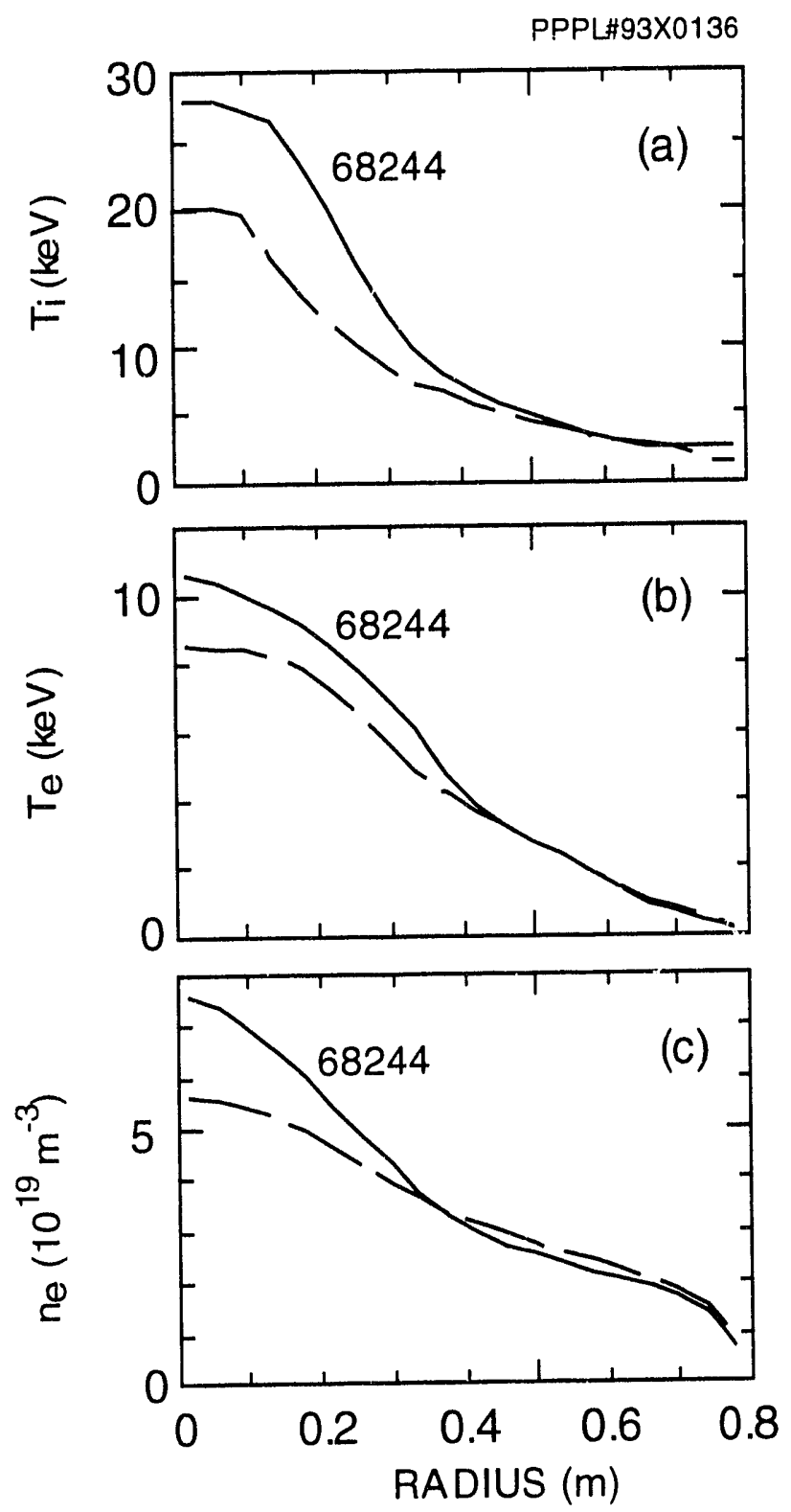

Fig. 4. Radial profiles of $n_{e}, T_{e}$ and $T_{i}$ for shot 68244 with Li pellet injection and comparison shot 68206 with no pellets. 


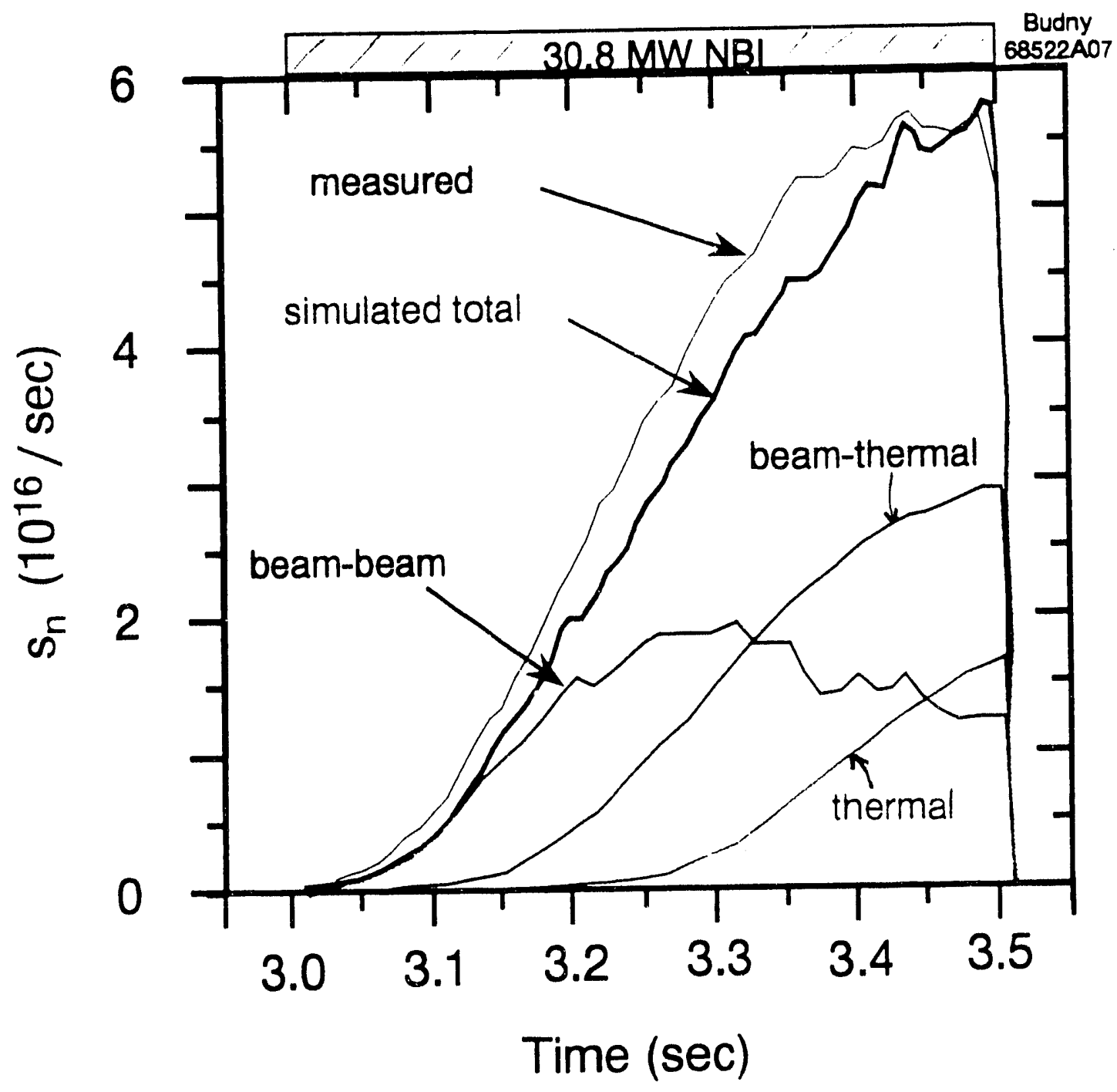

Fig. 5. TRANSP simulation of shot 68522 showing the time dependence of the 3 sources of fusion reactions. 

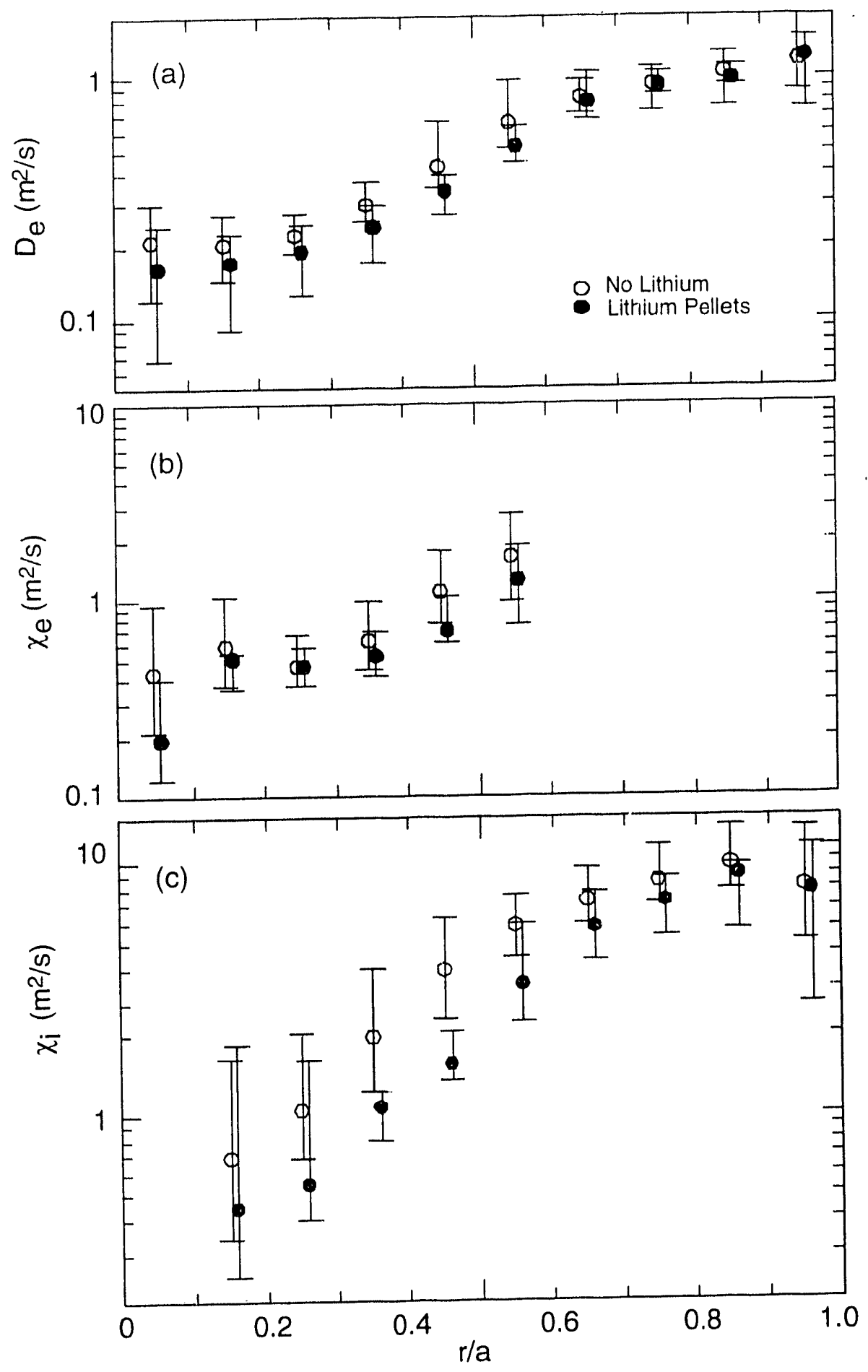

Fig. 6. Median transport coefficients calculated by SNAP for 180 supershots with no $\mathrm{Li}$ conditioning and for 5 exceptional shots with $\mathrm{Li}$ conditioning. 


\section{EXTERNAL DISTRIBUTION IN ADDITION TO UC-420}

Dr. F. Paoloni, Univ. of Wollongong, AUSTRALIA

Prof. M.H. Brennan, Univ. of Sydney, AUSTRALIA

Plasma Research Lab., Australian Nat. Univ., AUSTRALIA

Prof. I.R. Jones, Flinders Univ, AUSTRALIA

Prof. F. Cap, Inst. for Theoretical Physics, AUSTRIA

Prof. M. Heindler, Institut for Theoretische Physik, AUSTRIA

Prof. M. Goossens, Astronomisch Instituut, BELGIUM

Ecole Royale Militaire, Lab. de Phy. Plasmas, BELGIUM

Commission-European, DG. XII-Fusion Prog., BELGIUM

Prof. R. Bouciqué, Rijksuniversiteit Gent, BELGIUM

Dr. P.H. Sakanaka, Instituto Fisica, BRAZIL

Instituto Necional Do Pesquises Espacisis-INPE, BRAZIL

Ducuments Office, Atomic Energy of Canada Lid., CANADA

Dr. M.P. Bechynski, MPB Technologies, Inc., CANADA

Dr. H.M. Skarsgard, Univ. of Saskatchowan, CANADA

Prof. J. Toichmann, Univ. of Montreal, CANADA

Prof. S.R. Sreonivasan, Univ. of Caggary, CANADA

Prof. T.W. Jolunston, INRS-Energie, CANADA

Dr. A. Bolton, Centre canadien de fusion magnétique, CANADA

Dr. C.R. James, Univ. of Alberta, CANADA

Dr. P. Lukác, Komensketho Universzita, CZECHO-SLOVAKIA

The Librarian, Culham Laboratory, ENGLAND

Library, R61, Ruthertord Appleton Laboratory, ENGLAND

Mrs. S.A. Hutchinson, JET Library, ENGLAND

Dr. S.C. Shama, Univ. of South Pacific, FIJI ISLANDS

P. Mahonen, Univ. of Helsinki, FINLAND

Prof. M.N. Bussac, Ecole Polytochnique, FRANCE

C. Mouttet, Lab. de Physique des Milieux lonisés, FRANCE

J. Radot, CEN/CADARACHE - Bat 506, FRANCE

Prof. E. Economou, Univ. of Crole, GREECE

Ms. C. Rinni, Univ. of loamina, GREECE

Dr. T. Mual, Academy Bibliographic Ser., HONG KONG

Preprint Library, Hungarian Academy of Sci., HUNGARY

Dr. B. DasGupta, Saha Inst. of Nuctear Physics, INDIA

Dr. P. Kaw, Inst. for Plasma Resoarch, INDIA

Dr. P. Rosenau, Israel inst. of Technology, ISRAEL

Librarian, Intemational Center for Theo Physics, ITALY

Miss C. De Palo, Associazione EURATOM-ENEA, ITALY

Dr. G. Grosso, Istituto di Fisica del Plasma, ITALY

Prof. G. Rostangni, Istituto Gas lonizzati Del Cnr, ITALY

Dr. H. Yamato, Toshiba Res Devel Conter, JAPAN
Prof. I. Kawakami, Hiroshima Univ., JAPAN

Prof. K. Nishikawa, Hiroshima Univ., JAPAN

Director, Japan Atomic Energy Research Inst., JAPAN

Prof. S. Itoh, Kyushu Univ., JAPAN

Research Into. Ctr., National Instit. for Fusion Science, JAPAN

Prof. S. Tanaka, Kyoto Univ., JAPAN

Library, Kyow Univ., JAPAN

Prol. N. Inowe, Univ. of Tokyo, JAPAN

Secrotary. Plasma Section, Eloctrotochnical Lab., JAPAN

S. Mori, Tectniced Advisor, JAERI, JAPAN

Dr. O. Mitarai, Kumamoso Inst. of Technology, JAPAN

J. Hyeon-Sook, Korea Alomic Enorgy Research Inst., KOREA

D.I. Choi, The Korea Adv. Inst. of Sai. \& Tech., KOREA

Prof. B.S. Liley, Univ. of Waikato, NEW ZEALAND

Inst of Physics, Chinese Acad Sci PEOPLE'S REP. OF CHINA

Library, Inst. of Plasma Physics, PEOPLE'S REP. OF CHINA

Tsinghua Univ. Lbrary, PEOPLE'S REPUBLIC OF CHINA

Z. L, S.W. Inst Physias, PEOPLE'S REPUBUC OF CHINA

Prot. J.A.C. Cabral, Iristituto Superior Tecnico, PORTUGAL

Dr. O. Petrus, AL I CUZA Univ., ROMANIA

Dr. J. de Villiers, Fusion Studies, AEC, S. AFAICA

Prot. M.A. Hellberg, Univ. of Natal, S. AFRICA

Prof. D.E. Kim, Pohang Inst. of Sci. \& Toch., SO. KOREA

Prot. C.I.E.M.A.T, Fusion Division Library, SPAIN

Dr. L. Stonfio, Univ. of UMEA, SWEDEN

Library, Royal Inst. of Technology, SWEDEN

Prol. H. Wilheimson, Chalmers Univ. of Tech., SWEDEN

Contro Phys. Des Plasmas, Ecolo Polytech, SWITZERLAND

Bibliothook, Inst. Voor Plasma-Fysica, THE NETHERLANDS

Asst. Prof. Dr. S. Cakir, Middle East Tech. Univ., TURKEY

Dr. V.A. Glukhikh, Sci. Res. Inst. Electrophys.l Apparatus, USSR

Dr. D.D. Ayutov, Siberian Branch of Academy of Sai., USSR

Dr. G.A. Elisoev, I.V. Kurchatov Inst., USSR

Librarian, The Ukr.SSR Academy of Scionces, USSR

Dr. L.M. Kovrizhnykh, Inst. of General Physics, USSR

Kemforschungsanlege GmbH, Zentralbibliothok, W. GERMANY

Bibliothek, Inst. For Plasmatorschung, W. GERMANY

Prot. K. Schinder, Ruhr-Universitát Bochum, W. GERMANY

Dr. F. Wagner, (ASDEX), Max-Planck-Institut, W. GEAMANY

Librarian, Max-Planck-Institut, W. GERMANY

Prof. R.K. Janev, Inst. of Physics, YUGOSLAVIA 

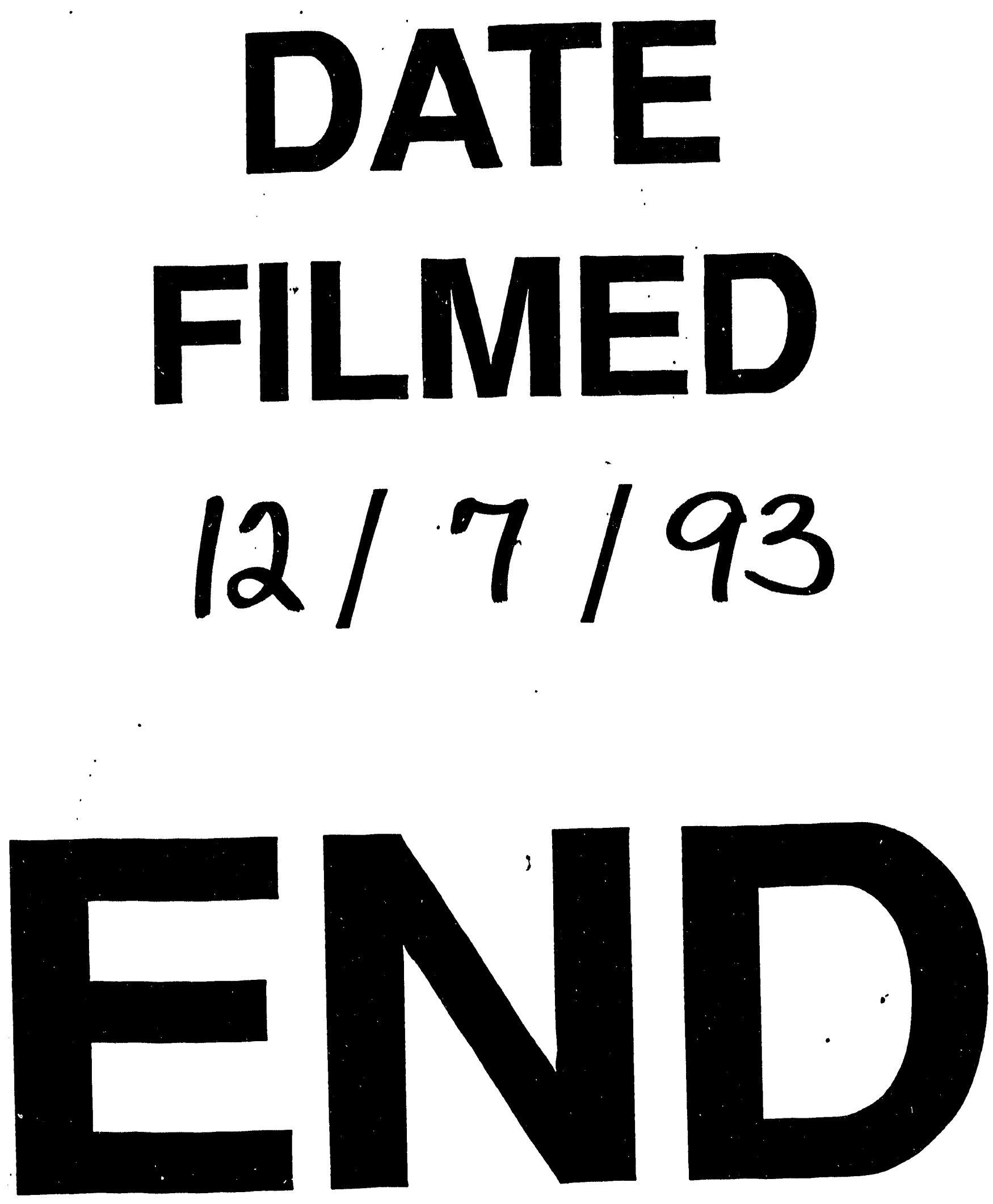
